\title{
LA CAPACIDAD POBLACIONAL DE ESPAÑA
}

\section{Los criterios sobre la capacidad pablacional}

Ya Aristóteles observaba que «no es lo mismo una gran ciudad que una ciudad populosa»; más aún, que una ciudad muy poblada, superpoblada no puede ser grande, por encontrarse internamente dividida, y que "debe haber una norma adecuada para el tamaño de una ciudad, como hay un tamaño normal para todo lo demás: animales, plantas, instrumentos, etc.»'.

En un reciente simposio demográfico, y en la sección «Sobre el problema de la capacidad de sustentar», J. M. Street observaba cómo con frecuencia se entiende esa expresión como "posibilidad permanente de alimentar» ${ }^{2}$, consideración tan obviamente necesaria como, veremos, insuficiente para determinar la posibilidad global, real, de mantenimiento de una población.

Para delimitar mejor la capacidad poblacional, muchos demógrafos, como Kurt Scharlau en el simposio citado ${ }^{3}$, recurren al concepto de población óptima, que sería el límite que separa la subpoblación de la superpoblación ${ }^{4}$. En la curva logística, correspondería al punto medio de inflexión, entre un mínimo y un máximo posibles en unas condiciones dadas ${ }^{5}$.

'Politica, VII, 4. (Para datos complementarios sobre las obras citadas en las notas, consúltese la bibliografía adjunta.)

2 En Kuls, p. 353.

3 Ibidem, p. 337.

+ Rappard, en Fromont, 1847, p. 150.

5 Clarke, 1953, p. 104. 
A. Sauvy, uno de los autores que más ha insistido en este concepto de población óptima, la define como "la que asegura de manera más satisfactoria la realización de un objetivo determinado» ${ }^{6}$. Polemizando, como siempre, con él, Bouthoul critica el óptimo de población porque «permite presentar bajo un aspecto científico las preferencias éticas, estéticas y políticas de cada cual» ${ }^{7}$. Y en España, Saranyana denuncia con Taglicarne esa «subjetividad" del concepto de óptimo de población ${ }^{8}$.

Sin embargo, la utilidad del concepto de óptimo de población proviene precisamente en parte de esa su manifiesta subjetividad, que nos ayuda a deslindar el campo de los fines (o preferencias) del de los medios (o métodos científicos) y no caer, como es tan frecuente en demografia, en un ingenuo determinismo cientifista, naturalista o providencialista. «Hay tantos óptimos de población como ideales» ${ }^{9}$. El papel de la ciencia (demográfica u otra) no es la de proporcionarnos ideales «científicos», sino la de mostrarnos la coherencia entre los distintos valores y los métodos para realizarlos, y sólo así — pero es mucho- ayudarnos a escogerlos ${ }^{10}$.

Sólo un análisis desapasionado, que distinga los medios de los fines, conseguirá evitar el extremo del moralista que, proyectando en los demás su autosuficiencia, producto de su falta de estudio de la realidad, condena a los que no piensan como él a la hoguera o al paredón por asociales, y el extremo opuesto del racionalista que no tiene en cuenta los intereses creados y cree que todo comportamiento asocial es producto de un mero error curable con una mayor educación.

En nuestro estudio iremos analizando los distintos óptimos de población teniendo en cuenta la agricultura, industria, defensa, espacio, etc. Y no sólo veremos que «hasta ahora no se ha logrado establecer ningún índice sencillo y satisfactorio de la superpoblación o de la población insuficiente» ", sino que tendremos que denunciar como ingenua utopía la pretensión de llegar a una síntesis «sencilla y satisfactoria» entre ideales que son complejos y, en los sistemas existentes, incluso antagónicos («mantequilla o cañones»), a nivel nacional e internacional. Una población óptima equilibrada, en sentido estricto, sólo será posible en un sistema global al menos relativamente óptimo y equilibrado, en cuya búsqueda (como proyecto final) y vías de acceso al mismo debe colaborar la demografía como las demás ciencias.

- Mil novecientos sesenta y tres, I, IV.

7 Mil novecientos sesenta y cuatro, p. 99; véase p. 146.

- Mil novecientos setenta y tres, p. 50.

9 Fromont, 1947, p. 156.

10 A. Dumont, 1901, p. VIII. "Las estadísticas demográficas, con su sequedad y precisión, nos ayudan a conocer un poco mejor el gran misterio de las costumbres /.../ nos manifiestan la manera de vivir de los hombres, la concepción que tienen de sí mismos, de su propio cuerpo, de su existencia familiar: sus actitudes ante la vida" dice Ariès, explicando la intención de toda su obra (1948, p. 13).

"Naciones Unidas, 1953, p. 249. 
La capacidad de alimentación de España

Es clásico, como ya hemos visto, relacionar la capacidad poblacional con la capacidad de sustentación de un territorio, en su sentido más estricto de producción de alimentos. Conectando los equívocos respecto a la capacidad agrícola con los de la capacidad espacial general, contribuye con frecuencia a nutrir el concepto de la gran capacidad poblacional española la exaltación de los grandes espacios vacíos existentes en la Península, máxime en ese interior en donde suelen vivir muchos de los que pregonan esa "grandeza» poblacional: «ancha es Castilla». Muchos de ellos se basan en la afirmación de Wallace ${ }^{12}$ y Owen ${ }^{13}$ de que la humanidad no tendría que preocuparse por los problemas de población hasta que toda la tierra esté cultivada como un jardín. Apenas es necesario aclarar que eso sería un derroche tan impensable en capital y trabajo que no se lo podrían permitir, ni lejanamente, los países más superpoblados ${ }^{14}$.

Esos desiertos de población corresponden en España a un auténtico desierto, en el sentido corriente de la palabra: territorio de gran sequedad. Entre nosotros, dice Vázquez, «el hecho natural más decisivo para la pobreza de España parece haber sido la índole del sistema hidrográfico», con ríos no sólo insuficientes, sino «ladrones» que despojan a la superficie de sus sustancias útiles para la agricultura ${ }^{15}$.

Sin embargo, son muchos todavía los que se empeñan en solucionar - como las cuestiones de población- estos hechos físicos, no recurriendo a medidas científicas - por ejemplo, a un pluviómetro- sino a un ciego amor a la patria (mejor dicho, a la idea tan falsa que tienen de ella, que permite a veces creer que la desconocen). Así, Azorín, sobrecogido y escandalizado ante el verde nórdico, exclamaba: «A A lector querido, tú también crees en las patrañas y leyendas de la España árida, de la España desierto! » ${ }^{\text {th }}$, y el, en esto, no más «científico» Ramón y Cajal, que opone «los heroicos labriegos de nuestras mesetas esteparias» a los «felices habitantes de los paises de yerba» ${ }^{17}$.

Aquí también, como en lo referente al suelo, se niega el problema exaltando las duras condiciones del campo, con lo que se perpetúan. Vieja esrategia que encontramos desde el romano Ovidio hasta el ministro franquista Cavestany y sus arengas a los «hombres del agro», «caballeros labradores», «arquitectos de nuestro suelo, ingenieros de nuestra geografía», «ángel custodio, centinela alerta, guerrillero audaz en la defensa a sangre y fuego de las

12 Malthus, 1803, III, 1.

${ }^{13}$ SaUVY, 1963, I, XXIII.

is Malthus, 1803, III, IV, y Bouthoul, 1964, p. 51.

is Mil novecientos setenta y tres, p. 10. Véase Huguet en Velarde, 1969, p. 93, y VELARDE, 1965, p. 88.

16 En Fontans, 1957, p. 545.

17 Mil novecientos cuarenta y seis, p. 150. 
viejas virtudes de la raza», «de cuyo barro está hecho el mejor ser de Europa y en cuyos surcos está escrita la mejor historia del mundo» ${ }^{18}$. Arenga que se quedó sin público porque, como veremos, en cuanto pudieron esos caballeros labradores dejaron el surco, ese ángel voló a la ciudad, escapando de esas condiciones inaceptables en que se le quería mantener con vanos halagos.

Ya una persona tan poco sospechosa a este respecto como José Antonio Primo de Rivera sostenía que no había que encadenar el campesino a la tierra, que hay que devolver al desierto y, sobre todo, al bosque muchas tierras que sólo sirven para perpetuar la miseria de quienes las labran» ${ }^{19}$.

Es difícil poner el problema «sobre bases terrenales», porque, conscientes o inconscientemente, hay que luchar con una multimilenaria tradición de exaltación de la tierra española como un vergel, un paraíso, un edén, según la cantara, entre mil otros, Alfonso $\mathrm{X}$ el Sabio ${ }^{20}$. Algunos, para intentar compaginar de alguna manera esos raptos líricos con la prosaica realidad, hablan de un cambio climático milenario ${ }^{21}$. Pero esta hipótesis -independientemente de su valor objetivo- no explica la continuidad de esas exaltaciones en los siglos posteriores, en los que el conocimiento del país podía ser además más completo.

Esa veneración y adoración de la tierra patria, esa fe en lo invisible -inexistente - que más que mover montañas o las ignora o las hace florecer, multiplicando hasta el infinito el milagro de la vara de Josué y saca agua de las piedras como Moisés, toma formas monoteístas resistiéndose a distinguir zonas dentro de esa tierra patria ${ }^{22}$. La realidad es muy distinta de esa mítica igualdad. Según la conocida clasificación de Mallada, reproducida por Tamames, el país cuenta con un 10 por 100 de rocas desnudas; un 35 por 100 de terrenos muy poco productivos (por altitud, sequedad o mala composición); un 45 por 100 de terrenos medianamente productivos y sólo un 10 por 100 de terrenos buenos ${ }^{23}$.

La conclusión es clara: esas exaltaciones de la capacidad de sustentación agrícola de España, si son moderadas, bay que reducirlas a la mitad (como el territorio cultivable); si son fuertes, si la declaran un edén, a su correspondiente 10 por 100; con las consecuencias correspondientes en el campo poblacional, como iremos explicitando.

A ésta ya tan limitada capacidad física de producción de alimentos bay que añadir todavia la fuerte limitación social de la producción; es decir, todos aquellos usos y costumbres que impiden en mayor o menor grado el

18 A. DE Miguel, 1975 , p. 150.

19 Obras, 1942, Discurso en Valladolid, 3-III-1935.

${ }^{20}$ Gómez OCaÑa, 1916, p. 138.

${ }^{21}$ MeYriat, c. II.

${ }^{22} \mathrm{Y}$ aunque esa unidad se realice por lo bajo, por la pobreza: "Decimos que la diversidad de regiones tiende a romper la unidad de los hombres, pero hay un factor natural que sí refuerza la unidad de España: la pobreza", VÁzquEz, 1973 , p. 10.

${ }^{23}$ Mil novecientos setenta y cuatro, p. 9. 
óptimo aprovechamiento de los recursos naturales realmente existentes: actitudes ante el trabajo, técnicas productivas, sistemas de propiedad, etc. ${ }^{24}$. Sólo el último de los factores citados, tan estudiado en nuestros días, constituye un enorme freno a la capacidad productiva, tanto por la inadecuación de las parcelas que ofrece al cultivo (desde el minifundio al latifundio) como por su influencia en la cantidad y calidad del esfuerzo productivo.

También hay que tener en cuenta la enorme erosión de origen social de nuestro suelo. En el aspecto económico, en España se quemaban bosques enteros desde la prehistoria para las minas, y después para la Mesta ${ }^{25}$, siendo frecuente hasta 1980 la quema de bosques para «valorizar» terrenos y por luchas sociales. En el campo político se ha empleado también la tala e incluso la política de tierra quemada, durante milenios, y tampoco está ausente en nuestros días. En modo muy especial, diríamos con el ecologista Osborn, «España revela una historia en la que las armonías y discordias entre hombre y hombre fueron transmitidas, a su vez, a la misma tierra» ${ }^{26}$. Hemos erosionado y quemado nuestra tierra. Si la palabra griega Pirineos expresa ya esos constantes incendios, habría que concluir tristemente que en España «todo son Pirineos». Si queremos sobrevivir, hemos de cambiar nuestra mentalidad bélica, no sólo para con nuestros vecinos y compatriotas, sino para con la misma naturaleza, pensando en ella no en términos de conquista, sino de convivencia armoniosa ${ }^{27}$.

Son muchos los utópicos que consideran que las limitaciones sociales a la producción de alimentos no son importantes, y que no es por tanto «serio» el tenerlas en cuenta al calcular la capacidad de un país para sustentar una población, pues «basta con cambiar esas costumbres». Pero la experiencia histórica demuestra sin excepción que induso en los raros casos en que se ha conseguido un cambio relativamente revolucionario en algunas de las condiciones sociales de elaboración de alimentos no han dejado de subsistir graves problemas a este respecto. En cierto sentido, es más fácil cambiar la naturaleza que las costumbres. Y en todo caso, hay que exigir a esos optimistas que esperan todo de una revolución política o técnica que tengan la mínima prudencia que observan los «salvajes», que sólo tienen la orgía después de la cosecha; es decir, que no llamen a la existencia más seres antes de estar seguros de que ya hay medios suficientes para mantenerlos adecuadamente ${ }^{28}$.

${ }^{24}$ Véase, por ejemplo, R. Dumont, Population, octubre-diciembre 1951, pp. 594 y siguientes.

${ }^{25}$ OSBORN, 1953, p. 19.

${ }^{26}$ Ibidem.

${ }^{27}$ Se recordará el ensayo de K. E. Boutding, quien ante la tierra cerrada del futuro observaba cómo pediría unos principios diferentes de la tierra abierta de antaño, de la "cowboy economy" (Hardin, 1964, p. 115). La misma objetivación de la tierra como infimo oasis que han resaltado los vuelos espaciales han ayudado a esta toma de conciencia (Callahan, 1871, p. 84).

${ }_{28}$ Bouthoul, 1964, p. 191. 
Los que, por unas y otras razones, tienden a reducir el problema de capacidad de población al del sustento en alimentos, gustan emplear a este respecto la expresión «superpoblación absoluta», reservando a las demás el de «superpoblación relativa». Debemos demistificar esa terminología como anticientífica, destinada objetivamente a perpetuar errores. Si hubiera una causa de superpoblación que fuera absoluta, y las demás relativas, no cabe duda que la causa importante sería la absoluta, y las demás estarían a una distancia infinita, como lo divino de lo que no lo es, ya que este concepto proviene del lenguaje sagrado y, por su misma etimología, significa - como el concepto de lo sagrado - lo separado, aislado, independiente. Pero la ciencia no conoce nada realmente aislado, diferente. $\mathrm{Y}$ si analizamos el concepto de superpoblación por carencia de alimentos, veremos que no tiene nada de absoluto, diferente, respecto a las demás causas de superpoblación: no es único, por ser igual para todos, porque varían los límites en que es tolerable el hambre según el clima, costumbre, etc.; no es único por ser el límite de vida o muerte, pues también otros tipos de superpoblación llevan a la muerte por contaminación, stress, etc.; y ni siquiera se distinque por ser siempre el último freno a la población, puesto que las poblaciones pueden ser frenadas e incluso eliminadas por factores distintos, sin que intervenga la alimentación.

\section{El reparto mundial de alimentos y la industrialización}

En sentido en parte opuesto a los que sólo piensan que existe una «superpoblación absoluta», hay que advertir contra quienes menosprecian los problemas agrícolas, y declaran que la industrialización alcanzada permitirá comprar sin problemas alimentos en el exterior. Porque este "pacto colonial» es forzosamente transitorio: los demás países se irán industrializando y necesitarán sus excedentes para sus poblaciones crecientes en número y en consumo. Ya, clarividente, Malthus advirtió a los ingleses contra esa especialización industrial que permitiría que aumentara su población muy por encima de sus posibilidades agrícolas ${ }^{29}$. Y cuando después de la segunda guerra mundial pareció que iba a darse una real descolonización, los dirigentes ingleses reconocieron en efecto que entonces tendría que emigrar como fuese casi la mitad de la población ${ }^{30}$. Sólo el éxito (para ellos) del pacto neocolonial permitió, hasta el presente, en Inglaterra y demás países industrializados ${ }^{31}$,

29 Mil ochocientos tres, III, IX, y III, XII.

30 Asi escribía The Observer el 10-XI-1946: "Hay que hacer todos los esfuerzos posibles para ayudar a cuantas personas se pueda, entre los doce millones que sobran (en Gran Bretaña), a dejar esta isla condenada a la escasez, para que vayan a cualquier parte del Imperio británico que pueda consentir recibirlas." (Reboux, 1951, p. 140.)

${ }^{31}$ Sin sus materias primas importadas, en especial el petróleo, "de los $54 \mathrm{mi}$ llones de ingleses que viven en las islas británicas sobrarían 30" (A. Guillén, 1962, p. 57). Sobre los Estados Unidos, véase Bouthoul, 1964, p. 117, y Sagrera, 1974a, Apéndice I. 
posponer esa crisis de materias primas, que la actual crisis del petróleo no hace sino replantear én términos cada vez más crudos ${ }^{32}$.

El que el imperialismo español actual no sea directamente político, sino que vaya a remolque del imperialismo económico de las naciones más desarrolladas, no debe hacernos olvidar que disfrutamos de una prosperidad basada en la expoliación de la gran mayoría de la población mundial, y que el día, quizá no lejano, en que perdamos ese injusto privilegio nuestras posibilidades globales de subsistencia, tan artificialmente mantenidas, se verán brutalmente mermadas ${ }^{33}$. Hay que estar bien ciego, como Engels en 1895 , para creer que no hay peligro de superpoblación porque hay muchos barcos cargados de trigo en los muelles de Londres ${ }^{34}$. Esa prolongada permisibilidad del aumento de población no es otra cosa, objetivamente, que un apoyo a una estructura poblacional imperialista, un refuerzo a la doctrina del «Lebensraum», a costa no sólo de la soberanía de otros territorios, sino, cada vez más, del hambre de sus cada hora más numerosos nativos, a quienes en plena carestía se les arrebata su sustento, como nos muestra la misma historia contemporánea ${ }^{35}$. Y hace falta tener todo el cinismo de un Colin Clark para decir, desde su despacho de funcionario inglés, que si la India y otros Gobiernos nos venden esos alimentos es porque sus pueblos no necesitan comer tanto, y hay que dejarles hacer lo que quieran (sus dirigentes hambreadores, claro está) ${ }^{36}$.

Contra la mistificación difundida por los mismos intereses de los países industriales de que la demanda de productos alimenticios, «limitada por las paredes del estómago" es inelástica, no expansiva, hay que reconocer los hechos: cada vez se amplian más las "paredes del estómago" de cada uno de los habitantes de los países industrializados, no sólo en su sentido más inmediato y obvio de obesidad, sino, sobre todo, en su sentido cualitativo, en que su elasticidad es prácticamente ilimitada: es decir, que cada vez con-

"2 García Fernández escribe que "el hecho de que esta parte de la vieja y densamente poblada Europa se haya convertido en una zona de inmigración constituye uno de los acontecimientos más sorprendentes de nuestro tiempo. Al acabar la segunda guerra mundial, el paro obrero era uno de los problemas principales con los que se enfrentaba la mayor parte de estos países" (1965, p. 55). La "sorpresa" debería referirse en todo caso al éxito de su neocolonialismo económico. El limitarse a reseñar sólo esta consecuencia poblacional no dice mucho en favor del autor, que, como veremos, se deja "sorprender" con frecuencia $y$ siempre en el mismo sentido.

33 Ya Fichte escribía que "en cuanto al comercio, Europa tiene una gran ventaja sobre las demás partes del mundo, apoderándose de sus fuerzas y de sus productos, sin proporcionar, ni de lejos, un equivalente adecuado de sus fuerzas y sus productos; que cada Estado individualmente, por desfavorable que le sea su balanza comercial respecto a los demás estados europeos, extrae con todo ciertas ventajas de esta común explotación del resto del mundo" (Denis, 1966, página 261 ).

"Werke, XXXV, p. 431 (Carta a Kautsky, 10-II-1983). Véase también MEsx. páginas $10 \mathrm{y}$ ss.

"SAGRERA, 1974a, pp. 245 y ss.

* Mil novecientos setenta, p. 110. 
sumen -consumimos- más proteínas nobles, lo que supone ocupar una porción de territorio destinada a producirlo muy superior. Este enorme crecimiento del consumo (muy superior en términos de alimentos al acelerado crecimiento poblacional en el mundo subdesarrollado) no se traduce en un aumento del precio de los productos alimenticios gracias a los «términos de intercambio» impuestos por los países industrializados. Así, en España, el porcentaje de gastos de alimentación descendió de 1958 a $1973-4$ de 53,3 a 38; el consumo de pan, pastas y cereales, de 100 a 91,7 . Por otra parte, subió el consumo de leche y sus derivados de 100 a 190 y el de carne de 100 a $259^{37}$.

\section{La capacidad de empleo. El bombre y la máquina}

Los economistas olásicos y marxistas han tendido a relacionar la capacidad de población no sólo con los alimentos o con el nivel de vida, sino también, y a veces preferentemente, con la de empleo ${ }^{38}$. Optica laboral que presupone una serie de conceptos sobre los que no es fácil llegar a un consenso: ¿qué es un trabajo productivo?, ¿cuál ha de ser su duración diaria y en la vida ¿hasta qué punto es un derecho y un deber? y ¿quiénes trabajarán?

Hoy día existe un amplio consenso en estimar que, en las condiciones existentes, un país se encuentra de becho superpoblado si la oferta de trabajo supera a la demanda más allá de un pequeño porcentaje friccional que se suele cifrar en torno al 3 por 100. Subrayamos el «de hecho" para indicar que no nos referimos a las hipotéticamente posibles, porque es también aquí frecuente la confusión, como en la discusión entre Sir Williams y Keynes, que sintetiza W. S. Thompson: «Si pensamos en la superpoblación como una condición que no puede darse mientras haya alguna manera concebible de dar más empleo y producir ingresos reales más altos, entonces parece que Sir William tenía razón... Por otra parte, si pensamos en la superpoblación como una condición en la que hay demasiadas personas para que se les pueda dar empleo con buenos salarios reales en las condiciones que ahora se dan y las que parece probable que se den todavía durante algún tiempo, entonces parecería que el profesor Keynes estaba en lo justo al decir que Inglaterra y Europa están superpoblados» ${ }^{39}$.

En España, como en 1980 el porcentaje de paro se aproxima al 11 por 100 , y la mayoría de las previsiones concuerdan en no sólo en que perma-

${ }^{37}$ INE, 1974, p. 185.

${ }_{38}$ Véase, por ejemplo, MARX, El capital, I, c. XXV, donde, como muchos marxistas, cree oponer esta ley de población a la de alimentos de Malthus. Pero Malthus insiste muchas veces en que el límite de alimentos es sólo para países atrasados. En otro más adelantado "la medida exacta de la población de un país que se halle en tales circunstancias no será en realidad la cantidad de alimentos, ya que una parte de éstos se exportan, sino la cantidad de empleo" (1803, III, $\mathrm{XIV}$, donde insiste varias veces en esta idea).

39 Petersen, 1965, p. 49. 
necerá, sino que aumentará, incluso notablemente, no parece dudoso deducir de esa reconocida grave situación de desempleo una peligrosa situación de superpoblación ${ }^{40}$.

En realidad, el problema es todavía mucho más importante y estable que el revelado por esa cifra. Porque ella se refiere a las personas consideradas activas, y los economistas están concordes que en España se consideran activas a muchas menos personas que en otros países europeos ${ }^{41}$; en particular por la postergación de la mujer, mucho menos aceptada laboralmente, en parte sin duda por esa sobreabundancia tradicional de población, siendo así, de un modo especial, engendradora de (más) hijos que la hacen superflua ${ }^{42}$; discriminación que la lleva, cuando se la acepta, a trabajar más horas ${ }^{43}$, en puestos inferiores, peor retribuidos. Con reminiscencias freudianas, escribía J. Leguina que la población femenina es el «colchón» que utiliza el sistema para aliviar sus tensiones en este sentido ${ }^{44}$. Ya en 1953 se escribía sobre los países participantes en la segunda guerra mundial que «la experiencia de la guerra ha demostrado que la magnitud de la población económicamente activa puede ser muy variable» ${ }^{45}$.

Viviendo, como inconscientemente muchos intelectuales, en «el mejor de los mundos posibles», Leibniz se asombraba de que se pudiera dudar en emplear máquinas, que sirven para actuar con menos esfuerzo (labor, dolor) por miedo a dejar sin empleo ${ }^{46}$. Pero el hecho es que en las sociedades superpobladas se elimina incluso aquellas máquinas primitivas que son los animales (caballar, bovino) porque compiten en subsistencia con la población: así en el sureste asiático ${ }^{47}$. Y todavía en la década de 1950, R. Dumont testimoniaba escandalizado cómo España era el único lugar de Europa en que había observado esta competencia entre el hombre y ese tipo de máquinas, los animales de tiro y de carga ${ }^{48}$. La superpoblación, entre otras cosas, pone o mantiene al hombre, en este como en otros aspectos, como veremos, al nivel de las bestias.

* El paro, como cualquier fenómeno social real, es la resultante de una serie de factores: poblacional, económico, político, técnico, cultural, etc. Un ejemplo entre mil del carácter marginal, residual, casi anecdótico, que se da al factor poblacional lo da un reciente estudio del Banco de Bilbao, en que se califica de "paro demográfico" sólo al paro de Canarias, y no al de Badajoz o Andalucia (de la que un dirigente señalaba hace poco que "todo está parado menos la demografía"), ni al paro de las zonas de mayor inmigración del pais (Hoja del Lunes, Madrid, 28-IV-1980). En todas esas regiones el factor de excedentes poblacionales juega inmediata y mediatamente un papel muy concreto y poco estudiado y menos tenido en cuenta para buscar las soluciones, que hoy exigen emplear todos los medios a nuestro alcance.

4I INE, 1974, p. 113; Tamames, 1974, I, p. 45; Rodríguez Osuna, 1977, p. 61.

42 SAGRERA, 1972; en particular pp. 192 y ss.

4 INE, 1974, p. 132.

4 Rodríguez Osuna, 1977, p. 58.

45 Naciones Unidas, 1953, p. 115.

4h Frohneberg, 1930, p. 30.

7 SAuvy, 1963, I, VIII.

${ }^{48}$ R. Dumont, 1951, p. 598. 
Sin duda, ya incluso entonces, esta situación era la excepción, y no la regla en España. Pero esto no se debe a que haya disminuido la superpoblación. Al más alto nivel técnico en que nos encontramos una generación después, la lucha es cada vez mayor en todo el país contra la máquina, a la que la superpoblación hace ver no como la amiga que alivia el trabajo, sino como la competidora que expulsa y elimina al hombre en todos los sectores de la economía.

En la agricultura, como cruenta guerra civil (que divide incluso internamente las familias, donde la compra de un tractor obliga a emigrar a algunos de sus miembros) la maquinaria para labrar, cosechar, etc., ha provocado durante el franquismo mil guerrillas, frondas de tipo luddistas $y$, hoy día, huelgas dirigidas legalmente por sindicatos que defienden una menor productividad, un tipo de trabajo más fatigoso y un mayor coste para todos los productos alimenticios y materias primas agrícolas, para evitar el paro y otros males a esa parte de la población que trabaja en el sector primario ${ }^{49}$. ¿Qué dato más elocuente al respecto que el que proporciona el mismo gobierno, que a las fincas que consigan el rendimiento agrícola adecuado con sólo un 70 por 100 , o incluso menos, del personal considerado como necesario, en lugar de darles un premio, les amenaza nada menos que con la expropiación? ${ }^{50}$.

En un pais muy y permanentemente superpoblado como de becho es et nuestro se considera, pues, a la máquina como «enemiga del hombre»; al inventor, o empresario ahorrador de trabajo, como un hambreador, un homicida; al que trabaja a conciencia, como un rompehuelgas que impide que otro y otros encuentren su sustento. El trabajo, lento, y por eso mismo largo, aburrido y desganado, se hace todavía más pesado por la carencia relativa de máquinas y la poca productividad; y la poca productividad, aun independientemente de la agravación de la superpoblación y otros factores negativos, lleva a disminuir el nivel de vida, en acelerado círculo vicioso de subdesarrollo. Una empresa, una obra, se valora no a pesar, sino precisamente porque obligará a trabajar a un gran número de personas. Al haber tantas, su esfuerzo no sólo se desprecia, sino que resulta una carga de la que hay que procurar desprenderse como sea, aun a costa de desperdiciar (también) otros recursos: así se subvencionan (a costa de todos) obras improductivas porque harán trabajar a muchas personas.

¿Qué de extraño tiene que esta desvalorización social del trabajo humano se interiorice, y que el trabajador, al menospreciar el resultado objetivo de su actividad, termine por despreciar su misma actividad (que no puede cambiar, pues no hay empleos vacantes, y en el fondo todos sufren de análoga inflación desvalorizadora) y termine lógicamente por menospreciarse a si mis-

4 Actos simbólicos son las manifestaciones de parados sobre las máquinas, o la concepción de la máquina como manipuladora y tirana de los destinos humanos en la obra de teatro de Salvador Távora Andalucía amarga.

${ }^{50}$ Boletin Oficial del Estado, 11-IV-1980, pp. 7815-16. 
mo como superfluo? Pocas alienaciones son tan graves y generalizadas como la propiciada por la superpoblación: la inflación, el abaratamiento y la desvalorización del hombre por el hombre. Y si consideramos el «clásico» desprecio español hacia la vida, y hacia el trabajo, podremos barruntar también hasta qué punto este factor de superpoblación está enraizado e influye negativamente en nuestro país.

La solución a este conflicto entre hombres y máquinas no puede estar, para nosotros, en rechazar las máquinas, como Vespasiano, con un paternalista: "Dejadme alimentar al pobre pueblo»" "Dicen los que gobiernan China: 'nosotros no podemos tener demasiada mano de obra'. Esto es porque ellos quieren utilizar esas manos como instrumentos, sin tener en cuenta a los hombres a los que pertenecen. Incluso desde un punto de vista económico éste es un mal sistema» ${ }^{52}$. La solución real está, como los mismos dirigentes chinos han ido comprendiendo y practicando estos últimos lustros, en combinar una prudente mecanización con una fuerte limitación del crecimiento de la población.

\section{Superpoblación nacional y emigración}

El desempleo larvado, subempleo, discriminación laboral por edad y sexo y otros factores pueden ocultar parcialmente el problema del paro, que por esas razones habría que duplicar o incluso triplicar respecto a las cifras oficiales. Sin embargo, hay otras cifras que manifiestan que el sistema no sólo no tiene capacidad para emplear en un momento dado a grupos importantes de la población, dejándolos parados, «di-funtos» ( $\sin$ función), sino que su incapacidad laboral es tan grande y permanente que no puede ni retener en su territorio a otros grupos muy numerosos, expulsándolos de un modo más o menos perdurable: son los emigrantes españoles.

El número total de personas nacidas en España que hoy viven fuera de sus fronteras puede cifrarse en más de tres millones de personas, en su casi totalidad activas ${ }^{53}$, lo que equivaldría a un 15 por 100 de la población activa. Este porcentaje, sumado al del desempleo en 1980, nos da que el sistema no tiene capacidad para emplear a un tercio de su población. Y esta estimación es mínima porque no incluimos en ella el desempleo larvado femenino, etc.

¿Cabe una prueba más patente de que (en las condiciones existentes y racionalmente previsibles, repitámoslo de nuevo) España está superpoblada? Tan evidente es el hecho, que sólo en torno al problema emigratorio en-

" Mandet, I, IV.

"FABRE-Luce, 1962, p. 32. Corresponde a la mentalidad mercantilista, como Fredro, quien en 1660 decía que el país tenía muchos brazos; "tenía mucho, por no decir todo" (Lipinski, p. 250).

s: Ignacio Fernández de Castro, 1973, p. 128. 
contramos en los últimos decenios algunas alusiones oficiales a una superpoblación del país ${ }^{54}$. Pero como reconocer con todas sus consecuencias la superpoblación española habría llevado a rechazar el ideal proclamado de «grandeza» de la España de «los 40 millones» ${ }^{55}$ e incluso de "los 60» ${ }^{56}$, y los intereses económicos y políticos correspondientes, se encubrió hipócritamente la conveniencia económica y política que tenía para los detentores del régimen esa emigración, conveniencia que llegó a ser vital a finales de los años cincuenta y obligó a la «apertura» emigratoria ${ }^{57}$.

Se dijo entonces que el Estado no «fomentaba», sino que sólo «canalizaba», la emigración ${ }^{58}$. González-Rothvos escribía en 1949 que «en nuestro país las circunstancias económico-financieras de España, a pesar de su indudable gravedad, no exigen imperiosamente una emigración masiva, como la italiana» ${ }^{59}$, por lo que, insistía Ruiz Almansa respecto a la emigración, no había «ni necesidad de estimularla ni conveniencia de impedirla» ${ }^{60}$. "Pero la Política racial española —empleada la palabra Política en su más alto y político sentido- aconseja la presencia de nuestra sangre en América, hacia donde debe ser dirigida, apartándola de otros países en los que no tenemos tales intereses raciales ni nos importa conservar en los mismos una Civilización nuestra" ${ }^{61}$; Ruiz Almansa concuerda con este criterio racista de González-Rothvos ${ }^{62}$ e insiste en otro lugar: «Si, como dice Rosemblat, el Continente está ganado para la raza blanca (y ello se debe en buena parte a la sangre hispánica), ¿no será de extrema conveniencia para aquellos pueblos mantener un aporte continuo de esa sangre para mantener el progreso de blanqueamiento y mestizaje y para impedir la acción de las fuerzas retardatarias o de retroceso?... Ello ha de ser indudablemente para nuestras generaciones nuevas un honor y un orgullo, probablemente también un deber y un sacrificio" ${ }^{63}$. ¡Y tan probable sacrificio! Ahí se le escapa a ese demógrafo, sentado en su butaca de Madrid, una amarga verdad que demagógicamente negara unos meses antes, cuando, en lugar de señalar las causas económicas y poblaciones reales que obligaban a exiliarse a millones de sus compatriotas,

${ }^{34}$ Fraga IrIbarne, Revista Internacional de Sociología, julio-septiembre 1950, página 248, según recensión de Ruiz Almansa; y García Fernández, 1965, p. 21.

ss Salustiano del Campo Urbano, 1974, p. 40; A. DE Miguer, 1977, p. 86, quien observa que, a veces, se habló incluso de 40 millones "de bayonetas". Puesto que no se entregaban bayonetas a las mujeres, esto pediría una población de unos 200 millones de personas...

s6 Calculada por cierto demógrafo, si se hubiera seguido la politica de los Reyes Católicos (sic) (Aguirre, p. 21).

57 Tamames, 1973, p. 413; Garcia Fernández, 1965, p. 27; Beaujeu-Garnier, 1956. página 92.

s8 José Serrano Carvajal (Velarde, 1965, p. 111).

${ }^{59}$ Revista Internacional de Sociologia, abril-septiembre 1949, p. 197.

${ }^{60}$ Ibidem, D. 332.

${ }^{61}$ lbidem, p. 197.

${ }^{62}$ Ibidem, D. 332.

${ }^{63}$ R.I.S., enero-marzo 1947. Sobre el racismo de Rosemblat, véase Sagrera, $1947 b$, p. 349. 
mistificaba que la conveniencia de que salieran «cada año 50.000 familias españolas» no era «para dejarse sus vidas y su sangre en el extranjero a cambio de un jornal, sino para colaborar con las poblaciones autóctonas hispanoamericanas en la elaboración de la cultura hispánica universal» ${ }^{64}$ y «al hacerse esta pregunta los padres y las madres de España: "¿Qué será de mis hijos?", se les puede contestar: "Tus hijos serán lo que ellos quieran, según sea su deseo de trabajar y su capacidad para el trabajo, porque hay diez millones de kilómetros cuadrados sobre el globo terráqueo sobre los cuales pueden estar como en su casa, y cien millones de seres humanos con los cuales pueden entenderse en la lengua de unos antepasados comunes, y con los cuales pueden convivir y ganarse la vida, sin sentirse expatriados ni desarraigados de su raíz y de su tronco racial, cultural, social y humano"» 65 .

No todos los grupos dominantes estuvieron de acuerdo con la emigración, porque no todos se aprovecharon por igual de los emigrantes. Algunos se quejaron e incluso quisieron impedir la emigración, porque con ella se les fue la mano de obra barata, que les permitía un modo primitivo de explotación ${ }^{66}$. De ahí la nueva «contradicción» que - no sabemos si por ignorancia o por otra causa- deja también estupefacto a García Fernández: «En el momento en que nuestra emigración ha alcanzado la mayor importancia de su historia, uno de los obstáculos que oficialmente se admite que encuentra el Plan de Desarrollo es la escasez de mano de obra» ${ }^{67}$. El hecho es que la emigración forzó la industrialización: «En España, por ejemplo, la obtención de la demanda final de 1970 con la tecnología de 1962 habría exigido un 63 por 100 más de empleados que los existentes en $1970 »{ }^{68}$. Así, poco a poco, España se industrializa, pasa a formar parte de los países que no ganan «el pan con el sudor de su frente», y a merecer también demográficamente los denuestos de García Fernández contra «los pueblos que no han tenido el coraje de soportar la carga de una infancia numerosa», «no tuvieron arrestos para darle vida», como diría con un trasnochado mercantilismo poblacionista ese viril admirador de «la gran natalidad del tiempo de Hitler» ${ }^{69}$. No es difícil que un esforzado profesor añore los fecundos braceros

64 R.I.S., julio-diciembre 1946, p. 439.

65 R.I.S., julio-diciembre 1946, p. 441.

os Tamames, $1974 \mathrm{I}$, p. 41. Sobre un ejemplo parecido en la Inglaterra decimonónica, véase MARX, El capital, c. XXIII.

${ }^{67}$ Mil novecientos sesenta y cinco, II.

68 Julio Segura, citado por Rodriguez Osuna, 1977, p. 68. Ya Mill puso un ejemplo, incluso cuantitativamente parecido al caso español: "Si se trasladara a las colonias una décima parte de los trabajadores ingleses $/ \ldots /$, se reduciría la demanda de alimentos; las tierras labrantias de peor calidad dejarian de cultivarse y se dedicarian a pastizales", subirían los salarios, etc. (1849, IV, V, I).

69 García Fernández, 1965, p. 64. A. de Miguel muestra un ejemplo parecido en E. Montes: "Lo que se envidia de España es su hombría; lo que el hombre técnico, fabril, fisiócrata, clubman, malthusiano y spenceriano, liberal y maquinistico, capitalista o socialista, confortable y frigorífico, filántropo de gastos y pardo puritano no le perdona al español es que sea, a más, hombre." (1975, p. 272; subrayados nuestros.) 
que ganaban el pan con el sudor de su frente; pero nos permitimos dudar que sus añoranzas sean compartidas por ellos, que a la primera ocasión han «desertado» ${ }^{70}$ esos empleos esclavizantes.

La emigración constituye, pues, un barómetro claro e incontestable paral medir parte de la enorme presión poblacional de la España contemporánea. La larga tradición emigratoria española es también muy elocuente para manifestar hasta qué punto es secular nuestro problema poblacional. Y respecto al futuro, el retorno de medio millón de emigrados a Europa en el último lustro " y una proporción irmportante de la emigración americana, no sólo contribuye a agravar nuestra superpoblación actual, sino que, por el carácter permanente y creciente de esta cerrazón de nuestra salida poblacional, nos indica neta y perentoriamente la necesidad de reformar a fondo nuestros esquemas en el campo demográfico, como en los demás. Se han cerrado las últimas fronteras de expansión, hemos llegado a tocar -incluso a chocar dolorosamente, ser rechazados, devueltos- la realidad de «un mundo limitado", y la falta de conciencia de este hecho no hará sino agravar nuestros males.

Todos los españoles, y en particular los que hemos padecido la emigración, tenemos el derecho y el deber de denunciar una ideología racista e imperialista, que trafica con hombres, obligándoles (aunque sea respetando las leyes del mercado) a expatriarse, cubriendo sus manejos con una bandera española enarbolada con tonos racistas o culturales, y aprovechándose también de su duro, discriminado trabajo en el extranjero.

También hay que denunciar cuanta mistificación subyace a las untuosas declaraciones de grupos que no se distinguieron nunca por su liberalismo, pero que hoy repiten como una letanía el derecho del hombre a emigrar. Porque mucho más primario y capital es el silenciado derecho del hombre a no tener que emigrar, gran trauma consciente o inconsciente para quien lo padece ${ }^{72}$. Y no es fácil concebir casos más patentes de manipulación que este lamentar por un lado la necesidad de emigrar y obstaculizar por otro, por todos los medios coactivos a su alcance, una limitación adecuada de la natalidad; más aún, fomentar con exhortaciones vehementes una proliferación que alimenta directamente esa emigración.

\section{Superpoblación regional y migración «interna»}

Los límites del presente análisis nos obligan, en general, a restringirnos a una visión de conjunto de los problemas poblacionales del país. Pero no hay

${ }^{70}$ García Fernández, 1965, p. 56.

${ }^{7}$ El País, Madrid, 30-VIII-1979. La C.E.E. teme una invasión de mano de obra española, oponiéndose a la libre circulación de la misma hasta el año 2000 ( $Y a$, Madrid 15-III-1980).

${ }_{72}$ López Cano, p. 155, quien cita a Pablo Neruda: "Pienso que el hombre debe vivir en su patria, y creo que el desarraigo de los seres humanos es una frustración que de alguna manera y otra entorpece la claridad del alma" (p. 1953). 
que perder nunca de vista la complejidad regional que los constituyen, y a la que en ocasiones es imprescindible referirse.

La superpoblación, y su expresión emigratoria, es más sentida en ciertas regiones españolas, de gran natalidad y pobreza, factores que, en general, se concadenan y agravan en lamentable círculo vicioso de subdesarrollo. Si en algunas de estas regiones priva la emigración exterior, como en Canarias, en otras, como en Andalucía, es todavía mayor la emigración interior que, a nivel nacional, $y$ en lo que va de siglo es muchas veces superior a la externa, y en forma creciente: de 1900 a 1970, 10.868 .725 españoles han abandonado su municipio de origen, de los que 3.719 .725 de 1960 a $1970{ }^{73}$.

El mito nacionalista de unidad nacional mecánica tiende a despreciar el coste humano de estas migraciones, suponiendo que todos los «sujetos» son piezas intercambiables ${ }^{74}$. La realidad es muy distinta, y su comprensión nos ayudará a calibrar la gravedad de este fenómeno de expulsión de la población «sobrante».

Si consideramos la emigración «interna» desde el punto de vista del lugar que se deja, es evidente que la ruptura es análoga para cualquier emigrante, externo o interno: todos deben dejar su lugar natal, su ambiente y paisaje originarios, su familia y amistades, y poner por medio una distancia salvable en la práctica sólo pocas veces por año, lo que en parte asimila también esta emigración a buena parte de las migraciones externas. En cierto modo, muy real y profundo, no existen migraciones «internas»: todas desarraigan, todas extraen al individuo de su medio natural y nativo, y el llamarlas «internas» no es en este contexto sino una mistificación, un intento hipócrita de negar la gravedad del fenómeno a que se somete a un porcentaje cada vez mayor de la población.

Incluso desde el punto de vista del lugar receptor, la diversidad existente entre los pueblos de España ha hecho que la integración de la migración «interna» se haya realizado a un coste humano no muy diferente de la externa, pues aun en el caso menos frecuente de que no hubiera entre ambos puntos, el de partida y el de llegada, un cambio de ambiente tan fuerte como el que existe entre lo rural y lo urbano, sí existía la diferencia entre una sociedad tradicional y otra moderna, industrial, sin que faltara incluso una barrera idiomática $y$ un enfrentamiento político-cultural seculares en

${ }^{73}$ FOESSA, 1975 , p. 68.

14 Escribe Lafont: "En la época moderna, los imperativos de la expansión capitalista han considerado además a los hombres, los 'ciudadanos', como masas de mano de obra económica que es legítimo desplazar de un extremo a otro del territorio nacional, rompiendo las raíces que ligan al nativo a su país, a su familia, a su cultura. La razón de Estado y el mito de la unidad intelectual nacional han tenido como resultado el que, bajo capa de Patria, se han fabricado verdaderos apátridas. Pero la razón de Estado cede siempre ante la lógica del capitalismo. La existencia de Estados nacionales celosos de su autarquía no ha impedido que los italianos del Sur, los españoles $/ . . /$, vayan a proletarizarse a la Francia del Norte." (1967, p. 247.) Véase también el estudio de V. Packard A Nation of Strangers. Nueva York, D. Mckay, 1972. 
dos de los tres puntos de más frecuente inmigración: Cataluña y el País Vasco; en el tercer punto de inmigración, Madrid, el cambio cultural era sin duda menor, recibiendo además inmigrantes geográficamente también más cercanos, pero proporcionaba también menos asideros económicos para la integración ${ }^{75}$.

Estos problemas de las migraciones internas deberán ser tenidos en cuenta cada vez más, al reconocerse hoy más no sólo el derecho a la propia identidad cultural de las zonas de inmigración, sino también la de las zonas de emigración, es decir, el valor de la cultura andaluza, extremeña, gallega, etcétera, $\mathrm{y}$ por tanto el derecho que tienen sus nativos a un medio digno de subsistencia sin tener que renunciar a sus propias raíces y, en un sentido si se quiere parcial pero muy real, expatriarse.

Sólo con una política poblacional adecuada podremos reparar los gravísimos daños causados a todas estas regiones por esa inhumana manipulación y desarraigo de las poblaciones. Sólo así se evitarán que continúen e incluso aumenten las reacciones extremas por parte de pueblos que se han visto próximos a perderse, en el sentido más estricto de la palabra. Por una parte, los receptores de inmigrantes. La provincia de Barcelona tenía en 1970 sólo un 52 por 100 de autóctonos; Alava, 59 por 100; Vizcaya, 60 por 100; Guipúzcoa 65 por $100^{76}$, estando, pues, cercanas a una alienación cultural y humana. Por otra parte, los pueblos de Andalucía, Extremadura, etc., veían extrañarse una parte de su élite y su fuerza de trabajo que esa sangría les hacía cada vez más débiles y colonizados ${ }^{77}$. En los últimos tiempos, como hemos visto, el problema migratorio interno no sólo no se ha resuelto, sino que se ha agravado. El interés de todos está, pues, en una creciente disminución del mismo, atacando para ello su raíz económica y poblacional, para que esta superpoblación no siga generando conflictos entre nosotros.

\section{La baja densidad y gran urbanización españolas,} sintomas de superpoblación

Uno de los temás más tenaces dentro de la compleja mitología de la grandeza poblacional española es la de su baja densidad, mito que profesan incluso reconocidos especialistas. Así, en 1978, el Instituto Nacional de Estadística concluía su encuesta de fecundidad observando que, puesto que la densidad poblacional de España era de 70 habitantes por kilómetro cuadrado (67 en 1970), frente a los 250 de Alemania o los 321 de Bélgica, no

${ }^{75}$ Véase FOESSA, 1975, pp. 68-69, y J. SALCEDo, Madrid culpable, p. 183.

${ }^{76}$ INE, 1974, p. 60, y A. G. Barbancho, 1975, pp. 115 y ss.

7 Serigó, p. 113. 
sólo no hay, sino que incluso en un futuro previsible, «no habrá problema especial de población en España» ${ }^{78}$.

Sin embargo, es anticientífico hablar de densidad en general, en absoluto. Aun dentro de un parecido estadio técnico - como el que tenemos con Europa- sólo es válido comparar la capacidad poblacional de dos territorios cuando son aproximadamente iguales, proporcionan unos medios de sustento análogos.

Al hablar de densidad, el concepto predominante es el de capacidad agrícola. Pues bien, aun dentro de esta óptica tan limitada para evaluar la capacidad de sustento de una población, óptica que podríamos llamar neolítica, es ya un simplismo muy mistificador dividir la superficie total de España por la de sus habitantes y concluir que puesto que el cociente es inferior al promedio europeo, España está poco poblada. Porque, como ya indicamos, la capacidad de sustento de los territorios es muy diferente. Sinteticemos con palabras de Tamames: "En general, el suelo de España es, desde el punto de vista agronómico, de calidad mala o mediocre» y sólo la mitad del mismo tiene capacidad agrícola» ${ }^{79}$. Ponderando, pues, con Vincent la población por la superficie de cultivo, hace ya tiempo que la densidad española no sólo se acercaba a la europea, sino que superaba incluso a la francesa ${ }^{80}$, en vez de ser una densidad más de cuatro veces inferior, según se deduce de una simple, simplista división de la población por los kilómetros cuadrados «brutos».

Pero incluso una densidad poblacional ponderada agrícolamente no nos dice mucho en un país que, como la España actual, tiene sólo una sexta parte de su población activa en la agricultura ( 25 por 100 en 1970,49 por 100 en 1960 y 60 por 100 en 1900$)^{81}$, y ha visto también reducir al 13 por 100 el aporte del sector agrario a la renta nacional ${ }^{82}$.

La desigualdad de las tierras de España manifiesta la falacia de colocar (mentalmente) en cada kilómetro cuadrado a 70 españoles. Pero, en teoría, el que ya sólo un sexto de ellos deban trabajar la tierra podría suscitar la esperanza de suplir la desigualdad agrícola del suelo repartiendo con mayor regularidad a esa gran mayoría que no depende de la agricultura. En realidad, el sistema técnico agrícola neolítico tendía ya a acentuar la desigualdad en el reparto de la población respecto a los sistemas pastoral y cazador, y el actual sistema industrial multiplica esa desigualdad.

7 Página 41. (Nos referimos al folleto, no al libro publicado sobre este tema.) También Baselga se basaba en la densidad por kilómetro cuadrado para decir que "faltaba mucho" para que el mundo y España pudieran considerarse superpoblados (1964, p. 57).

${ }^{79}$ Tamames, 1973 , p. 19; 1974, I, p. 9.

80 Beaujeu-Garnier, 1956, II, III. Villar Salinas justificaba en 1942 la España de los 40 millones diciendo que Portugal tenia 77 habitantes por kilómetro cuadrado (A. de Miguel, 1977, p. 101).

${ }^{81}$ Anuario Estadistico español, 1978.

32 Tamames, 1973, p. 125. 
En nuestro país, si el sistema agrícola fomentaba un desigual reparto entre el interior y la periferia, según el clásico estudio de Román Perpiñá ${ }^{83}$, estas diferencias se han ido acentuando cada vez más, y en forma vertiginosa en los últimos lustros ${ }^{84}$. El censo de 1960 mostró que mientras la densidad nacional promedio estaba en aumento, un 44 por 100 de su superficie estaba compuesta por provincias que perdían población. En 1970, el porcentaje subió al 60 por $100^{85}$; y desglosando el territorio por municipios, la superficie que pierde población en 1960-1970 (decenio en que la densidad nacional promedio crece como nunca en este siglo) es nada menos que el 81 por $100^{86}$.

Estas enormes y crecientes desproporciones en la distribución espacial de la población están relacionadas con el ser hoy España una de las naciones más urbanizadas, aglomeradas del mundo. El porcentaje de habitantes en poblaciones de más de 20.000 habitantes era en 1970, en Francia, de 41 por 100; en Italia, del 52 por 100, y en España, del 54 por 100, frente a un promedio europeo - $\sin$ Rusia, que tiene un 42 por $100-$ del 45 por $100^{87}$.

Datos para 1977 dan una densidad para la provincia de Barcelona de 591 habitantes por kilómetro cuadrado, y para Madrid de 571, es decir, unas sesenta veces más que Soria, con 9,8, o Teruel, con 10,2, dentro de un promedio cada vez más engañador de $72,4^{88}$. Y si tenemos en cuenta que en 1900 la densidad de Barcelona era de 136 y la de Madrid 97, mientras que la de Soria era de 15 y la de Teruel 18 , observaremos que en lo que va de siglo las regiones más densas han cuadruplicado su población, y las menos han reducido mucho la suya, haciéndose las diferencias entre ellas, de 6 a 60 , diez veces mayores ${ }^{89}$.

A nivel mundial, el problema de superpoblación se presenta cada vez más como problema de aglomeración, de hacinamiento ${ }^{90}$, agravado por las técnicas modernas de comunicación ${ }^{91}$. «Vivimos en una densidad mucho más fuerte de aquélla para la que la evolución genética ha modelado nuestra es-

a3 Perriñá, 1952, 1954, 1965.

84 FOESSA, 1970, p. 87; Tamames, 1974, I, p. 29.

8. INE, 1976, p. 83.

${ }^{86}$ Ibidem, p. 94. La densidad rural disminuye de 1950 a 1970 de 27 a 23 personas por kilómetro cuadrado, entendiendo por rurales los municipios de menos de 20.000 habitantes (A. de Miguel, 1977, p. 183).

87 A. DE Miguel, citado por Serigó, 1977, p. 128.

8 "En un territorio de población tan rala como el español, partir de la hipótesis de una densidad homogénea supone una entelequia." (A. de Miguel, 1977, página 250). Un error tan fácil de cometer como grave a partir de esta situación es imaginar que ciertas provincias están mejor porque sube su renta por persona, cuando esto se debe sólo a que su población disminuye todavia más deprisa que sus riquezas, como observaba un reciente estudio del Banco de Bilbao (Serigó, página 113).

39 Elaboración propia a partir de datos oficiales.

ot Dús, 1968, p. 167.

9 MCLUhAN, 1969, p. 62. 
pecie» 92. Ya Ortega y Gasset describía «el hecho de la aglomeración, del 'lleno'. Las ciudades están llenas de gente. Las casas, llenas de inquilinos. Los hoteles, llenos de huéspedes. Los cafés, llenos de consumidores, etc. Lo que antes no solía ser problema empieza a hacerlo casi de continuo: encontrar sitio» ${ }^{93}$; y denunciaba que Europa se había convertido «en una prisión, donde se han amontonado muchos más presos de los que caben; ninguno puede mover un brazo ni una pierna por propia iniciativa, porque chocaría con los cuerpos de los demás» ${ }^{94}$.

$\mathrm{Si}$ en muchas regiones subdesarrolladas la superpoblación se define en buena parte en relación a los alimentos, en otras como la nuestra hay que insistir en que «tan importante como eso - -el problema de los alimentospara mantener la calidad de la vida humana es un ambiente en que le sea posible satisfacer el deseo de tranquilidad, privacidad, independencia, iniciativa y espacios abiertos. No son caprichos o lujos; constituyen reales necesidades biológicas" ${ }^{95}$.

No podemos detallar aquí los problemas de la aglomeración, al que hemos dedicado un análisis. Baste enumerar algunos, como el aumento de la agresividad individual y colectiva, de las dificultades de desplazamiento, reglamentación general, contaminación y costes económicos crecientes ${ }^{\%}$.

En España el problema de la superpoblación urbana es mucho más grave aún de lo que indican las ya tan elocuentes cifras reseñadas, que la colocan entre las naciones más urbanizadas, pues el ritmo de su urbanización ha sido también tan rápido que no ha permitido ni una adaptación relativa a esas lamentables condiciones de la ciudad moderna ${ }^{97}$. En 1900 vivían en municipios de más de cien mil habitantes cuatro veces menos españoles, en proporción, que en $1970^{98}$. Con una expresión que para nosotros es de humor negro. Melón observa que «del aumento de la población de España en el Censo de 1950 se han beneficiado principalmente los núcleos urbanos» ${ }^{99}$. Dudoso beneficio, que agrava singularmente, por la rapidez de la transformación, los numerosos problemas que plantea toda urbe moderna.

No se debe pues a un mero romanticismo trasnochado el que muchos habitantes de las grandes ciudades españolas consideren más satisfactoria la

92 N. TINBergen (J. Parsons, 1971, p. 159).

${ }^{93}$ La rebelión de las masas, c. I.

Ibidem, Prólogo.

93 Dubos, 1968, p. 169.

\% Véase SAgrera, Hacinamiento. Superpoblación y sexualidad.

${ }^{97}$ No es que sea deseable una adaptación completa a unas circunstancias malsanas; pero ni siquiera sacamos el provecho de ese doloroso desajuste, la conciencia de la necesidad real de cambiar el rumbo. Subrayamos lo de "real" porque idealmente el III Plan suponía que se iba a producir sin esfuerzo un milagro de desconcentración y su falta de previsión agrava nuestros problemas (A. de Miguel, 1977, p. 288).

${ }_{98} \mathrm{INE}, 1974$, p. 56.

9 Estudios Geográficos, año XIII, núm. 48, p. 446. A. de Miguel observa, en cambio, que "es evidente que algunas regiones desbordan ya un nivel tolerable de congestión metropolitana" (1877, p. 191). 
vida del campo ${ }^{100}$. «Nadie es feliz sino comparado», diriamos con Séneca, y aunque fueran discutibles algunos componentes de este juicio, su misma expresión denota una insatisfacción subjetiva consciente, y en cuanto tal, indiscutiblemente real, objetiva.

Dado pues el alto grado de concentración urbana de nuestro país, y la firme tendencia nacional y mundial, que sin excepción tiende a un fuerte aumento de esa concentración, se comprenderá cómo el intentar presentar como prueba de capacidad de más población la baja densidad española por kilómetro cuadrado no podrá ser, cada vez más, sino el producto de una gran ignorancia o mala fe. Precisamente el que cada vez haya más kilómetros cuadrados vacíos y se pueda hablar con razón estadística, superficial, de «despoblación de media España» ${ }^{101}$ manifiesta que en las condiciones actuales esas tierras ya son agrícolas o, al menos, socialmente infecundas, incapaces de sustentar a los niveles alcanzados por nuestra civilización la vida humana: son pues un testimonio de la limitación creciente en esa esfera de las posibilidades de aumentar la población, y no de lo contrario ${ }^{102}$.

No queremos con ello excluir la posibilidad de aprovechar mejor los recursos de regiones hoy despobladas. Pero su colonización no deberá confundirse, como antes, con su repoblación, ya que la experiencia mundial prueba cómo van unidos el aumento de productividad con la menor necesidad relativa de mano de obra, y el mayor nivel de vida ligado a la mayor productividad con una tendencia reforzada a la emigración rural. El Plan Badajoz constituye, entre nosotros, un elocuente ejemplo a este respecto ${ }^{103}$.

\section{La guerra como sangría poblacional, un secreto bien guardado}

En un país en el que se insiste tanto en el aspecto militar de la vida como España, cabría esperar una alusión más explícita por parte de los poblacionistas a tener más hijos «para defender la patria». De hecho son muchas las arengas para «dar hijos a la patria», «engrandecer España», contribuir así al «imperio», ya que sin aumentar la natalidad «no haremos de España una gran potencia» ${ }^{104}$. Con todo, lo de "gran potencia» y engrandeci-

100 REOP, julio-septiembre 1971.

101 J. DE LA Cuzva, en Serigó, 1977, p. 128.

102 En 1970, 22 de las 23 provincias que pierden población (se excluye Huesca) pertenecen a la España menos desarrollada (INE, 1976, p. 91). Véase Nadal, 1971, página 211.

103 PÉRez de Guzmán, 1973, p. 43: "En conclusión: el Plan Badajoz, concebido como una espoleta para el desarrollo, pero, sobre todo, como un medio para resolver los graves problemas sociales de la región y la provincia, se revela más bien, en gran medida, como un centro de reunión, clasificación y reenvio para muchos de los habitantes de la provincia que emigran a otras tierras más prometedoras."

104 "Nos encontramos, pues, ante un dilema: o España aumenta su natalidad - será detenida su ascensión al rango de gran potencia." (RIS, julio-septiembre 1944, p. 86; Ros Jimeno, RIS, julio-septiembre 1944, p. 86.) 
miento patriótico se puede entender, incluso en un país de mentalidad tan poco capitalista como el nuestro, en sentido económico, y el imperio se ha interpretado a veces —en contra de los puntos de la Falange, etc. - en sentido cultural.

Una posible explicación del poco recurrir a esta argumentación sería la racional: «El número no significa nada en la época de la técnica atómica adelantada, salvo la ignorancia de los que aún continúan razonando como si vivieran hace más de diez siglos» ${ }^{105}$. Pero sería irracional atribuir este relativo silencio de nuestros poblacionistas respecto al argumento militar a un convencimiento racional de su inanidad, cuando en los demás argumentos muestran menos mesura que sus colegas de otros países.

La explicación de este silencio se encuentra en la relación realmente existente entre población y guerra en nuestro país. En general, los gobernantes no solicitan con interés real a sus súbditos hijos para la guerra sino cuando existe una conquista colonial en curso o un «enemigo hereditario» con el que habrá que enfrentarse en la siguiente generación (como Alemania y Francia en 1870,1914 y 1939). En los demás casos, mucho más frecuentes en nuestros días, los gobernantes buscan por el contrario hacer la guerra para deshacerse de una población sobrante, que amenaza la estabilidad de su régimen; aunque, como es lógico, no expliciten por qué «el primer deber del soldado es morir por la patria» y no el hacer que el otro muera por la suya. Esta es la causa profunda, demoeconómica, de tantas guerras «sin sentido», según hemos expuesto, junto con múltiples autores, en otro lugar ${ }^{106}$.

Ahora bien: para realizar esta sangría que alivie los problemas de una región superpoblada, su Gobierno debe realizar una serie de inversiones socioeconómicas: encuadrar un ejército unificado en todo su territorio, alimentarlo, entrenarlo, armarlo y transportarlo conforme al nivel del enemigo que haya podido encontrar para que, quieras que no, alivie su propio problema.

Este esfuerzo está por encima de las posibilidades de un país pobre. Este tiene que recurrir a las (económicamente y de entrada) más baratas guerras civiles, que son, como agudamente las adjetiva un especialista, «la relajación del pobre» ${ }^{107}$. Francia, superpoblada al extremo a fines del siglo xvir, hasta ser conocida como "la China de Europa», tuvo una guerra civil «hasta el Terror», pidiendo, por ejemplo, Collot d'Herbois una «transpiración política» que eliminara la mitad de su población ${ }^{108}$, si bien consiguió después exteriorizar su agresividad en guerras fuera de sus fronteras, exportando la «fraternidad». Un siglo después, la Alemania sin «Lebensraum» harta de guerras civiles, sociales, aceptó como salvación la solución hitleriana de defender los «valores occidentales», primero contra los judíos de dentro de sus fronteras, y después contra los marxistas, plutocracias, etc. España, más pobre, no pudo

ins Prados, 1973, p. 23.

11K SAgrera, 1975, p. 43.

in Bouthoul. 1964, p. 31.

108 Duncan, 1929 , p. 340. 
defender esos «valores occidentales» ni, como consiguiente en parte la Italia de Mussolini, en Africa ${ }^{109}$. Tuvo que liquidar su exceso de población en st propia casa, ayudando algo a eliminar sus excedentes poblacionales a Italia y Alemania ${ }^{110}$.

Es posible que esta demistificación, este análisis demoeconómico del origen infraestructural de la revolución francesa o del fascismo alemán e italiano pueda haber encontrado eco respectivamente a derecha o izquierda, pero que en ambos campos hay quienes encuentren prosaico, degradante, «reducir» nuestra «Cruzada» o nuestra «defensa de la república» a un «mero» problema de población "'. Siempre es amargo tomarse la píldora de la moraleja, el «a ti se refiere el cuento», pero puede tener consecuencias muy saludables: porque si no se acepta este condicionamiento del fratricidio por la crisis demoeconómica no queda más explicación de las atrocidades de uno y otro bando que un racismo fatalista (que se emplea, por ejemplo, también contra los alemanes o rusos) que considera a los contrarios como alimañas que deben ser liquidadas, justificando un terror por otro terror.

La desesperación de los pueblos superpoblados que no son conscientes de serlo hace en efecto que escojan como salvadares precisamente a quienes prometen matar más gente, aliviando así (en forma cruel, pero aceptada al no haber conseguido otra) su excesivo número. Esto explica, sin necesidad de mistificaciones sobre razas crueles (que se «mutan» al cambiar esas circunstancias demoeconómicas) el que los pueblos soporten, más aún, apoyen entusiasmados a un Hitler en Alemania, un Marat, Robespierre o Napoleón en Francia o, entre nosotros, a una Inquisición, o a quien se declaraba dispuesto, como el revolucionario francés antecitado, a «fusilar a la mitad de España” para salvarla ${ }^{112}$.

Insistamos: el reconocer el condicionamiento demoeconómico de la agresividad es necesario, no sólo para reconciliarnos con el pasado (propio $y$ ajeno) sino por ser la única manera de impedir que, con nuevas modalidades, vuelva a repetirse. «Los pueblos que ignoran la historia se ven obligados a

In Es significativo al respecto la conexión con las guerras africanas de múltiples sucesos trascendentales, como la Semana Trágica de Barcelona y los orígenes de las dictaduras de Primo de Rivera y Franco.

1110 Junto con otras causas, contribuyó al encarnizamiento de nuestra guerra civil el ser muy elevada la natalidad de las clases dirigentes, por lo que habia menos posibilidad de ascenso desde las otras clases (Bouthoul, 1954, p. 340, y Gini en Becker, p. 1024).

"II Recordemos el origen demoeconómico de las Cruzadas a Oriente, confesado por su promotor, Urbano, en Clermont :"El pais que ocupáis, circundado por el mar y por altos picos montañosos, es demasiado estrecho para su gran población." (M. Pagano, 1949, p. 9.) En España, en las Cruzadas contra los moros, los pregones, como el del Cid para conquistar Valencia, comenzaban asi: "Quien quiera dejar trabajos - y su soldada ganar..." (Pedro Abad, p. 258.)

1: Franco al corresponsal de News Chronicle el 30 de julio de 1936; el coronel Barato, más moderado, declaró al del Toronto Star: "Habremos establecido el orden cuando hayamos ejecutado a dos millones de marxistas." (Broué, 1962, página 216.) 
repetirla» (Santayana). Y si no ponemos remedio, junto a los problemas económicos, a los poblacionales que los agravan, sufriremos cada vez más de la agresividad despreciadora de la vida que es fuente común de fenómenos en apariencia tan inconexos como los accidentes de tráfico y el terrorismo político ${ }^{113}$.

El que hace tiempo perdiéramos un imperio colonial y nuestra debilidad redujera nuestras guerras de sangría poblacional a guerras civiles, explica pues el silencio de nuestros poblacionistas en este punto. No es tan fácil solicitar más hijos para matar más vecinos y compatriotas, aunque éstos sean partidarios, por ejemplo, de don Carlos (de Borbón, Marx, etc.). Ha sido un secreto bien guardado, pero ya es hora de que desenterremos su raiz $y$ no nos limitemos a podar sólo algunas de sus manifestaciones.

\section{El tamaño óptimo de la familia}

Todas las acciones de los individuos, incluso las que en apariencia son más individuales, realizadas a escondidas y contra las reglas explícitas de la sociedad, como el suicidio, según demostró Durkheim, son producto genuino de la sociedad que modeló a quien las ejecuta ${ }^{114}$. Negarlo sólo puede ser fruto de una crasa ignorancia, o de una hipocresía que intenta evitar responsabilidades. No pueden pues juzgarse de otro modo declaraciones como la de un oficial mejicano: «nosotros dejamos absolutamente a juicio de cada familia el determinar los hijos que quieran tener" ${ }^{115}$. Porque la influencia del Estado, máxime en la sociedad moderna, es tal, que influye profundamente en toda la estructura social. Jugar al «laisser faire», al lavarse las manos, no puede engañar a nadie, aunque esta actitud de Pilatos sea asumida a veces, contra toda su ideología, por los mismos países comunistas; así el ruso Guerasimov dice que «como es lógico, el problema de los hijos se decide a nivel familiar y no estatal» "Cómo se puede ser planificador en un campo y liberal en otro? ${ }^{117}$. Ya Mill explicaba la evidencia de sentido común: «La sociedad puede alimentar a los necesitados, si controla su multiplicación, o puede desinteresarse de los que nazcan y abandonar a aquéllos a su suerte.

${ }^{113}$ G. Mouton, 1968, p. 17. Sólo el control de nuestra población evitará por esta parte que resuene de nuevo el grito de "Viva la muerte" en nombre de Dios. Marx o alguna otra no menos trágica excusa.

it Véase su monografía sobre El suicidio.

115 El Universal, Caracas, 2-1II-1976.

11 Mil novecientos sesenta y siete, p. 29. Es lo contrario de lo que dijera Lenin: "Beber agua es un asunto personal. Pero en el amor hay dos interesados, y viene un tercero, un ser nuevo": aunque hiciera estas declaraciones no para planificar la población, sino para reprimir puritanamente la sexualidad: "Los excesos en la vida sexual son un sintoma de degeneración burguesa." (Fréville. 1956, p. 294.) Véase también Coulet, 1952, p. 182.

117 G. Loyo, en Stycos, p. 44. 
Pero no puede impunemente tomar a su cargo la alimentación de los necesitados y dejar que se multipliquen libremente» 118.

Es explicable que, durante un período, y ante los estados tradicionales, autoritarios y poblacionistas, pareciera y fuera positivo exaltar los derechos del hombre, del individuo, el derecho a no tener más hijos que los deseados. Rara vez podría ser la urgencia de más población, que no pudiera obtenerse por inmigración, tan fuerte que constituyera una obligación moral el tener más hijos, y el no hacerlo constituyera pues una prueba de egoísmo, como denunciaban esos Estados codiciosos de peones económicos y políticos.

En nuestros días, en que individuos y Gobiernos están más de acuerdo en el derecho e incluso el deber de limitar la fecundidad, surgen voces de grupos e ideologías trasnochados que pretenden una libertad tan absoluta, tan individualista, tan abstracta como la anterior, pero en sentido contrario: y así encontramos a un funcionario español que reclama el derecho de los matrimonios a tener todos los hijos que deseen ${ }^{119}$. Hasta qué punto ese liberalismo no es sino el conocido caballo de Troya, el reclamar la libertad para acabar con ella, lo ponen de manifiesto las palabras de Bouthoul, de que la experiencia contemporánea «muestra que se pueden dar todos los derechos que se quiera al hombre y a la mujer, excepto el de procrear al azar o según su capricho. Porque entonces amenazan a los demás y hacen que la humanidad recaiga en las épocas de las matanzas, ruinas y genocidios" ${ }^{120}$. Un siglo antes, Drysdale denunciaba que «tener muchos hijos es el peor de todos los pecados sexuales que pueden cometer un hombre o una mujer. Apenas hay otra cosa que cause tanta miseria a los demás» ${ }^{121}$; de la misma Norteamérica a que se refiere Drysdale, por su consumo de recursos mundiales no renovables, las familias numerosas han sido comparadas hoy a «verdaderos vándalos" 12.2 .

En España, a pesar de las insistentes campañas en favor de las familias numerosas, campañas ( $\mathrm{y}$ familias) pagadas a costa de todos, encontramos ya en 1966, en nuestra encuesta demográfica, que casi el doble de los hombres y algo más de la mitad de las mujeres opinaban que no era bueno para el país el que hubiera familias numerosas que los que consideraban que sí lo era ${ }^{123}$.

118 Mil ochocientos cuarenta y nueve, II, VIII, 2. Y Fourier observaba que "entre las inconsecuencias y aturdimientos de la politica moderna, nada más chocante que el olvido de reglamentar el equilibrio de la población, relacionando proporcionalmente el número de consumidores con las fuerzas productivas. En vano se descubririan medios de alcanzar el cuádrupo y aun el céntuplo de productos si el género humano estuviese condenado a pulular como hoy (1946, página 1973 ).

${ }_{114}$ M. Garrigo Roca, jefe de servicios de puericultura, en Prólogo a G. Mauco, 1967, p. 15.

13it Mil novecientos sesenta y cuatro, p. 94 .

:21 Mil ochocientos cincuenta y cuatro, p. 361.

${ }_{122}$ R. Dumont, citado por A. de Miguel, 1975a, y Day, Too many Americans.

${ }^{123}$ Esperamos publicar en breve un análisis sobre Natalidad y control natal en España, ya realizado, que incluirá los resultados de esa encuesta. 
Y cuando se trata de concretar cuál es el número ideal de hijos por familia, el porcentaje de los que escogen un ideal de cuatro y más hijos es de sólo el 17,7 por 100 , descendiendo a sólo 2,4 si se piensa en cinco o más hijos ${ }^{124}$. El número ideal de hijos por familia en esta encuesta de 1977 era de 2,79 ${ }^{125}$, en un descenso continuo desde los 2,83 encontrados por FOESSA en $1974^{126}$ y los 3,32 de FOESSA en $1966^{127}$, así como los 3,4 que encontramos en nuestra encuesta de ese mismo año.

La encuesta del INE de 1977 dio también un número ideal de hijos para el encuestado de 2,63, inferior al ideal para todos, $2,79^{128}$; es decir, que los individuos tienden a desear tener ellos menos hijos de los que el ideal social les lleva a creer es bueno que tengan los demás, cifra ideal que a su vez es inferior al número real de hijos que de hecho tenían las mujeres de cuarentacuarenta y nueve años, $3,1{ }^{129}$.

Comparando este 3,1 hijos tenidos con el 2,63 deseado para sí, resulta pues que cada dos mujeres tienen un hijo confesadamente no deseado. La cifra total de hijos no deseados, que incluya a los no confesados (ni a sí misma) es muy superior, como revelan la encuesta de 1977 y la nuestra de 1966.

Estos datos nos muestran que el número real de hijos tenidos en España rebasa netamente el óptimo familiar adoptado ${ }^{130}$, óptimo ideal que es cada vez más bajo, según una corriente secular y mundial que no ha admitido sino breves excepciones coyunturales. $Y$ ese mismo becho de que las familias quieran menos bijos de los que tienen muestra que en ese sentido psicológico, pero muy real, consciente y vivido, las familias españolas están superpobladas ${ }^{13 !}$.

\section{La «grandeza» poblacional de España}

Desde los comienzos de la humanidad, la lucha por la supervivencia frente a una mortalidad que se llevaba a la mitad de los niños antes de la pubertad, llegando muy pocas personas a los sesenta-setenta años (que hoy

124 Encuesta del INE, 1978, p. 142. Véase también A. DE MiguEL, 1977, p. 63, donde observa que la proporción de mujeres de 40.45 años con cuatro o más hijos desciende en los veinte años que terminan en 1970 del 53 al 17 por 100.

12: INE, 1978, p. 193.

${ }^{12 t}$ FOESSA, 1975, p. 360.

37 FOESSA, 1969, p. 500.

128 INE, 1978, p. 145.

129 Ibidem, p. 75.

13:1) SAUvY, 1963, I, II. Comentando unas declaraciones del ginecólogo Santiago Dexeus de que la mitad de las criaturas nacidas no son deseadas, A. de Miguel observa que "aunque la frase es hiperbólica, no cabe duda de que la aplicación racional del momento en que positivamente se desean los hijos es todavia una actitud muy poco común" (1977, p. 83).

$13 t$ HrLl, 1959, c. I, sobre Puerto Rico. 
alcanza la inmensa mayoría de los habitantes de los países desarrollados), hacía que sólo en circunstancias muy excepcionales, físicas y socioeconómicas, el excedente de nacimientos pudiera llegar a crear problemas de superpoblación: el problema constante era impedir los avances de la mortalidad, la despoblación. Se comprende pues que se considerara señal inequívoca de buen gobierno el incrementar la población (lo que hoy se da hasta en los regímenes más opresivos y sanguinarios) y que los grandes mitos incitaran al incremento poblacional, como el «Creced y multiplicaos» de la Biblia ${ }^{132}$.

El control sobre la mortalidad reclamó un reequilibrante control sobre la natalidad, y en la medida en que se retrasó este control complementario se acumularon excedentes de nacimientos que han creado una situación de superpoblación en amplias regiones del mundo. En España, el control de la mortalidad fue muy lento hasta este siglo: todavía en 1920 moría más del 20 por 100 de la población antes de tener un año de vida (en 1920, el 2 por 100 , diez veces menos) y sólo llegaban el 10 por 100 a los setenta y cinco años (en 1970, el 55 por 100). Y cuando los progresos para restringir la mortalidad tuvieron éxito y reclamaron un control adecuado de los nacimientos, una cruenta guerra civil y sus secuelas impidieron una visión y ajuste racionales del problema, continuando e incluso reforzándose los viejos mitos poblacionistas, tan enraizados en la estructura militarista, imperialista y emigratoria de nuestra sociedad, que ya hemos analizado.

La noción de que España no sólo no tenía superpoblación, sino que era un país que necesitaba más población estaba pues apoyada tanto por una secular inercia intelectual como por un complejo de sentimientos religiosos y patrióticos, firmemente mantenidos por grupos interesados en el expansionismo, emigración, mano de obra barata, etc.; grupos que impedían cualquier análisis racional, objetivo, de las posibilidades poblacionales del país, como contrario a la grandeza de España. De ahí los enormes vacíos y contradicciones que se manifestaban en la política poblacional del Gobierno, según fueron señalando, desde los ángulos más dispares, personalidades como Ruiz Almansa ${ }^{133}$, Salustiano del Campo ${ }^{134}$ y Ramón Tamames ${ }^{135}$.

${ }^{132}$ El hombre moderno se encuentra todavía sometido a mitos impregados del antiguo pathos de tendencia expansiva, en un mundo ahora finito (véase Bianchi, p. 157).

${ }_{133}$ "No se ha llegado a perfilar una política general, adecuada, científica, consciente, de la población española" /.../ "La pobreza de nuestra literatura científico-demográfica /.../ se corresponde así con la inseguridad, o mejor, la inexistencia de una línea nacional de conducta en materia de población". RIS, abrilseptiembre 1947, pp. 332-333.

${ }_{134}$ "En nuestro país carecemos de politica demográfica manifiesta, cosa que no impide el estudio de nuestra política demográfica implícita. Y ello a pesar de que la ley de 24 de enero de 1941 (B. O. del Estado, 2 de febrero de 1941) afirmaba: la política demográfica es una de las preocupaciones fundamentales de nuestro Estado" (Sistema, enero 1974, p. 47).

135 "A pesar del tiempo transcurrido (desde 1969) y no obstante los planes de desarrollo, no existe aún una actitud oficial decidida sobre este importante problema del desequilibrio demográfico $-\mathrm{y}$ económico y social, en definitiva, 
Apenas es necesario subrayar la gravedad de la situación. ¿Cómo hacer una buena política sin conocer bien la población? ${ }^{136}$. ¿Cómo planificar y actuar bien sin tener una idea clara de nuestra capacidad humana, poblacional, respecto a nuestros recursos? Nos falta entonces, como decía Halbwachs, ese primer sentimiento que se tiene al volver a la vida después del sueño: el de conocer la posición del propio cuerpo, orientándose, conociendo sus límites, sin lo que sobrevienen problemas psíquicos, alucinaciones ${ }^{137}$.

$\mathrm{Ya}$ es hora de despertar, de tomar conciencia de ese capital elemento en nuestra crisis actual: que constituye la verdadera dimensión y orientación de nuestro cuerpo social, y dejar de administrar una dieta de engorde cuando en realidad padecemos de excesivo volumen, y debemos reducirlo ${ }^{138}$.

La conclusión central de nuestro análisis es que los datos expuestos nos impulsan urgentemente a renunciar al ideal tradicional de la «grandeza» de España, concebida de un modo cuantitativo y externo que cada vez nos perjudica más, porque el crecimiento cuantitativo, en las actuales circunstancias, daña el nivel cualitativo de nuestra existencia, tanto en lo material como en lo espiritual. Hemos de tomar plena conciencia de haber llegado al punto en que, en palabras de Calderón, «dar vida a un desdichado / es dar a un dichoso muerte» ${ }^{139}$, porque, en un mundo superpoblado, «el mayor delito / del hombre, es haber nacido» ${ }^{140}$. «Vuestro mero número -decía Ortegaes ya un crimen" ${ }^{141}$.

Hay que dar un giro coperniciano a la tradicional mentalidad poblacionista, si no queremos que en nuestro territorio, como, en sus características propias, en el resto del mundo, la excesiva proliferación de nuestra especie atente contra su misma vida. El Congreso español ha aprobado en 1980 el eliminar del escudo nacional el lema «una, grande, libre», acto que estimamos simbólico de un imprescindible cambio de mentalidad, que reconoce más la realidad y puede ajustarse mejor a ella. En nuestro tema, la unidad no puede ya concebirse «ideal» (falsamente) como una igual capacidad de todas las tierras de España, ni una intercambiabilidad entre los españoles como piezas mecánicas. La libertad de España tampoco puede entenderse como un derecho expansionista, por medio de sus emigrantes o de sus productos, sino una libertad relativa, reconocedora y respetuosa de la libertad ajena, democrática, en una palabra; concepción cada vez más necesaria en un mundo re-

e incluso político- del país" (1974, I, p. 36.) También A. de Miguel escribe en 1977 (p. 88): "En los últimos años, de un modo negativo, las autoridades estatales han ido comprometiéndose cada vez menos con cualquier política abiertamente (anti)natalista, aunque todavía se conceda cierta relevancia formal y litúrgica a la política de protección a las familias numerosas." (Colocamos entre paréntesis el "anti" porque el contexto muestra que es una errata.)

1.s Moheau, 1778, p. 12.

137 Página 201.

138 Rock, D. 63.

139 Fontana, 1957, p. 548.

140 En Campa, 1970, p. 458.

14 Barretro, p. 26. 
conocidamente limitado, en donde ya no cabe el «ancha es Castilla». Por último, la grandeza de España, insistamos en ello, no debe ser concebida como aumento cuantitativo, sino como el mejoramiento cualitativo, en todos los sentidos, de una cantidad de población adecuada para una convivencia sin roces ni conflictos consigo misma, con las demás poblaciones del mundo $y$ con el ambiente físico en el que se encuentra.

\section{BIBLIOGRAFIA}

Abad, Pedro: Poema del mío Cid, Madrid, Crisol, s. f. (1307).

Aguirre Prado, Luis: La población. Madrid, Publicaciones españolas, n. 366, 1958. ArIEs, Philippe: Histoire des populations françaises, París, Self, 1948.

Aristóteles: The Politics, Baltimore, Penguin, 1962.

Barbancho, A. G.: Las migraciones interiores españolas en 1961-1970, Madrid, Imprenta Nacional, 1975.

Barretto, Castro: Populaçao, riqueza e segurança, Río de Janeiro, Biblioteca do Exército, Ministerio da Guerra, 1961.

Baselta, E.; S. J.: Estudios de sociologia industrial, Madrid, Aguilar, 1964.

Beaujeu-Garnier, J.: Géographie de la population, París, L. de Médicis, 1956.

BECKER, H.: Social Thought from Lore to Science, Nueva York, Barnes Dover, 1961.

Branchr, U.: Teogonie e cosmogonie, Roma, Universale Studium, 1960.

Bouthoul, G.: Traité de sociologie, París, Payot, 1954.

- La surpopulation, París, Payot, 1964.

Brové, P.: La revolución y la guerra de España, México, Fondo de Cultura Económica, 1962.

Callahan, Daniel: The American Population Debate, Nueva York, Doubleday, 1971.

CAMPA, R.: Il pensiero politico lationamericano, Bari, Laterza, 1970.

Campo Urbano, S.: Política de población de España, Madrid, Cuadernos para el Diálogo, 1974.

- "Política demográfica de la familia y de la natalidad en España", Sistema, enero, 1974.

Clark, C.: ¿Hambre o abundancia?, Caracas, Tiempo Nuevo, 1970.

Clarke, G. L.: Elementos de ecología, Barcelona, Omega, 1963.

Couler, P.: Les problèmes de la fécondité humaine, París, Action Populaire, 1956.

DAY, L. H., y A. T.: Too many Americans, Boston, Houghton Mifflin, 1964.

Dents, H.: Histoire de la pensée économique, París, P.U.F., 1966.

Dryspale, Dr.: The Elements of Social Science, Londres, Truelove, 1898 (1854).

Dumont, A.: La morale basée sur la démographie, Paris, Schleicher, 1901.

Dumont, R.: "Les excédents démographiques de l'agriculture méditerranéenne", Population, octubre-diciembre 1951.

Duncan, H. G.: Race and Population Problems, Nueva York, Longmans, Green y Cía., 1929.

Engels, F., y Marx, K.: Werke, Berlín, Bietz, 1963.

FABRE-LUCE, A.: Men or Insects? A Study of Population Problems, Londres, Hutchinson, 1964.

Fernández de Castro, I.: La fuerza de trabajo en España, Madrid, Edicusa, 1973.

FOESSA, Fundación: Informe sociológico sobre la situación social de España, Madrid, Euramérica, 1966.

- Ibidem, 1970. 
- Estudios sociológicos sobre la situación social de España, Madrid, Euramérica, 1976.

Fontana, J. M.: Los españoles ante el año 2000. Madrid, Samarán, 1957.

Fourier, C.: El Falansterio, Buenos Aires, Intermundo, 1946.

Fréville, J.: La misère et le nombre, París, Editions Sociales, 1956.

Fronneber, E.: Bevolkerungslehre und Bevolkerungspolitik des Merkantilismus. Gelhausen, F. W. Kalbfleish, 1930.

Fromont, P.: Démographie économique, París, Payot, 1947.

García Fernández, J.: La emigración exterior de España, Barcelona, Ariel, 1965

Gómez Ocaña, Dr.: El sexo, el hominismo y la natalidad, Madrid, Calleja, 1916.

Guerásimov. G.: "Sobrepoblación del Globo", Enfoque internacional, octubre 1967.

Guillén, A.: El imperialismo del dólar, Buenos Aires, Peña Lillo, 1962.

Halbwachs, M.: Morphologie sociale, Paris, Colin, 1958.

Hardin, G.: Population, Evolution and Birth Control, San Francisco, W. E. Freeman. 1964 .

Hild, R.: The Family and Population Control, Chapel Hill, The University of North, Carolina Press, 1959.

Instrtuto NAcional dE Estadística: España. Panorámica social 1974, Madrid, 1974

- Panorámica demográfica, Madrid. 1977.

- Encuesta de fecundidad (diciembre 1977). Metodologia y resultados, Madrid, 1978.

KuLs, W.: Probleme der Bevolkerungsgeographie, Darmstad, Wissenschaftliche Buchgesellschat, 1978.

LAFONT, R.: La révolution regionaliste, Paris, Gallimard, 1967.

LIPINSKi, E.: De Copernic a Stanislaw Lesgegnyiski, París, P.U.F., 1961.

López CaNo, D.: "Algunas consideraciones sobre la emigración española", Cuadernos geográficos de la Universidad de Granada, núm. 8, 1978.

Malthus, T. R.: Ensayo sobre el principio de población, México, F.C.E., 1951 (1803)

Mandel, E.: Traité d'économie marxiste, París, Julliard, 1962.

MarX, K.: El capital, Moscú, Progress, 1965.

Mauco, G.: Regulación de nacimientos, Barcelona, Mateu, 1967.

McLuhan, M. H.: La comprensión de los medios como las extensiones del hombre, México, Diana, 1969.

MEEK, R. L.: Marx, Engels y la explosión demográfica, México, Extemporáneos, 1973 (1953).

Meyrat, J.: L'Espagne, Paris, Institut d'Études Politiques, 1961-2.

Miguel, A. DE: Sociologia del franquismo, Barcelona, Euros, 1975.

- Sexo, mujer y natalidad en España, Madrid, Cuadernos para el Diálogo, 1975a.

- La pirámide social española, Barcelona, F. J. March-Ariel, 1977.

Mill, J. S.: Principios de economía politica, México, F.C.E., 1943 (1849).

MoHEAU: Recherches et considérations sur la population de la France, París, P. Geuthner, 1912 (1778).

Mouton, G.: Le cannibalisme, religion davenir, Ginebra, Perret-Gental, 1968.

NACIONES UNIDAs: Factores determinantes $y$ consecuencias de las tendencias demográficas, Nueva York, 1953.

Nadal, J.: La población española, Barcelona, Ariel, 1961.

Ortega y Gasset, J.: "La rebelión de las masas", Obras Completas, Madrid, Revista de Occidente, 1930.

OsBorn, F.: The Limits of the Earth, Boston, Little, Brown y Cía., 1953.

Pagano, M.: Población y crisis, Rosario, Editorial Rosario, 1949.

Parsons, J.: Population versus Liberty. Londres, Pemberton, 1971.

Ṕrez de Guzmán, T.: Las familias agricultoras en el Plan Badajoz, Sevilla, Instituto de Ciencias de la Familia, 1873.

Perpiná, R.: De estructura económica y economía hispana, Madrid, Rialp, 1952.

- Corologia, Madrid, C.S.I.C., 1954.

- Problemas de los movimientos de población en España, Madrid, Anales de Moral social y económica, 1965.

Petersen, W.: The Politics of Population, Nueva York, Doubleday, 1965.

Prados Arrarte, J.: La población, Madrid, Guadiana, 1971. 
Primo de Rivera, J. A.: Obras Completas, Madrid, Diana, 1942.

Ramón y Cajal, S.: Mi infancia y juventud, Buenos Aires, Austral, 1946.

Reboux, P.: Trop d'enfants, París, Denoel, 1951.

Rock, J.: The Time Has Come, Nueva York, Avon, 1963.

Rodrfguez Osuna, J.: "Distribución espacial de la población en España", REIS, octubre-diciembre 1978.

Ros Jimeno, J.: "El decrecimiento de la natalidad y sus causas", RIS, julio-septiembre 1944.

SAGrera, M: El mito de la maternidad, Buenos Aires, R. Alonso, 1972.

- Hacinamiento, Caracas, Monte Avila, 1974.

- Explosión poblacional, economía y politica. Malthus, Marx y Suramérica, Buenos Aires, Astrea, 1974a.

- Los racismos en América "Latina", Buenos Aires, 1974b.

- El subdesarrollo sexual. Un análisis estadístico, Buenos Aires, Cuarto Mundo, 1975.

Salcedo, J.: Madrid culpable, Madrid, Tecnos, 1977.

SaRANyana, J. I.: Introducción a la historia de las doctrinas económicas sobre la población, Madrid, C. E. de Cajas de Ahorro, 1973.

Sauvy, A.: Théorie générale de la population, París, P.U.F., 1963.

Sericó, A.: La evolución de la población española, Madrid, Dirección General de Sanidad, 1977.

Srycos, J. M.: Human Fertility in Latin America. Sociological Perspectives, Ithaca, Cornell U. Press, 1968.

Tamames, R.: Introducción a la economía española, Madrid, Alianza, 1973.

- Estructura económica de España, Madrid, Guadiana, 1974.

- La polémica sobre los límites del crecimiento, Madrid, Alianza, 1974b.

Vázquez de Prada, V.: Historia económica y social de España, t. I, Madrid, C. E. de Cajas de Ahorro, 1973.

Velarde, J.: "La estructura económica de España y los movimientos de población", Anales de Moral social y económica, Madrid, 1965.

- Lecturas de economía española, Madrid, Gredos, 1969. 